\title{
OS PIABEIROS DE BARCELOS E AS REDES DE INTERDEPENDÊNCIAS
}

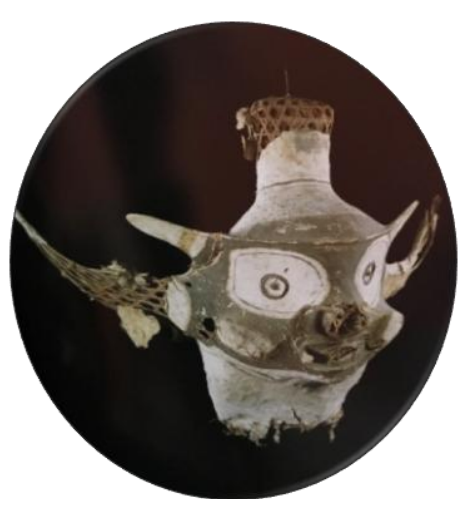

\author{
Josias Benfica da Silva ${ }^{1}$ \\ Gláucio Campos Gomes de Matos2
}

\begin{abstract}
Resumo
Este artigo busca revelar as redes de interdependências criadas pelas interações que entrelaçam o piabeiro, a pesca artesanal de peixes ornamentais e as relações de poder no município de Barcelos. Mostra da mesma forma, por meio de uma observação sistemática, como se desenvolvem essas relações sociais, apresentando dados estatísticos revelando a desvalorização desse pescador em contradição aos altos lucros dos patrões. É uma pesquisa bibliográfica, de aporte teórico e experiência de campo, a qual aponta as novas figuraçõesque estão em curso para uma maior valorização tanto do pescado quanto do pescador eapresentar o ethos e as práticas socioculturais desse amazônida.
\end{abstract}

Palavras-chave: Redes de interdependência. Piabeiro. Peixe ornamental.

\begin{abstract}
This article seeks to reveal the networks of interdependencies created by the interactions that interweave the piabeiro, artisanal ornamental fishery and power relations in the municipality of Barcelos. It shows in the same way, through a systematic observation, how these social relations develop, presenting statistical data revealing the devaluation of this fisherman in contradiction to the high profits of the bosses. It is a bibliographical research, theoretical contribution and field experience, which points out the new figurations that are underway for a greater appreciation of both the fish and the fisherman and present the ethos and socio-cultural practices of this Amazonian.
\end{abstract}

Keywords: Networks of interdependence. Piabeiro. Ornamental fish.

1Mestrando em Sociedade e Cultura na Amazônia; Licenciado em Letras Língua Portuguesa - UFAM; Pós-graduado: Gestão em Políticas Públicas e Gestão Escolar; Gestor Escolar - Escola Municipal São Vicente Professor da Rede Municipal de Ensino (SEMED-MAO)

2 Professor do Programa de Pós-Graduação Sociedade e Cultura na Amazônia da Universidade Federal do Amazonas. 


\section{INTRODUÇÃO}

As relações sociais no mundo rural amazônico são fontes inesgotáveis de pesquisas, as quaisretratam os conflitos que movimentam os atores desses beiradões3. Para Norbert Elias (2004), as relações sociais são teias de interdependências desencadeadas pelas interações humanas entre “eu” e o "tu”, entre o "nós” e o "eles", entre indivíduos diferentes e/ou iguais, em constante dinâmica geradora de fenômenos reticulares. Esta perspectiva apresenta as redes organizacionais, ou estruturas policêntricas, constituintes de figurações das sociedades contemporâneas. Nessa ótica, temos como foco o caboclo piabeiro4 - figura emblemática resultante do processo histórico da ocupação humana na região amazônica - inserido emfigurações, sustentado por relações de poder estabelecidas no processo de captura, negociação e exportação dos peixes ornamentais do rio Negro5.

Homem tranquilo, o caboclo nasce e vive em uma natureza que apresenta seus perigos, porém dominada e farta de movimentação. Ele traz em seu rosto os sinais das fornalhas tropicais e, embora provido de vários elementos étnicos além do índio, parece mais com o índio que pouco fala e pouco age. $\mathrm{Na}$ região do alto rio Negro, esse amazônida é conhecido como piabeiro - pescador de piabas ou peixes ornamentais. Seu local de trabalho é o rio, e é em sua canoa, quase sempre só, que tudo acontece. $\mathrm{Na}$ busca dos preciosos ornamentais ele desbrava os rios, os lagos, os igarapés, a mata e a imensidão do maior arquipélago fluvial do mundo - Mariuá; é parte do meio, por isso nunca se apressa e assim como outros trabalhadores braçais

3Designação dada aos locais na margem dos rios onde residem os ribeirinhos 4 Indivíduo conhecido na região do município de Barcelos/AM como pescador do peixe neon Cardinal (ParacheirodonAxelrodi) e outras variedades de peixes ornamentais.

5 É o mais extenso rio de águas negras do mundo e o segundo maior em volume de água. Principal afluente da margem esquerda do rio Amazonas. 
sofre e chora as incertezas de sua lida. Exímio pescador, esse piabeiro leva consigo o remo, o rapixé ou o puçá que são seus instrumentos de pesca.

O enfrentamento diário desse caboclo não se restringe às dificuldades do rio e da floresta, mas principalmente nas figurações onde se insere. Ele é visivelmente explorado pelos "patrões" que operam o aviamento nessa região, numa cadeia econômico-trabalhista de total desvalorização desse trabalhador. Tal situação nos despertou para entender essas figurações, visando analisar as relações decorrentes do processo de captura, negociação e exportação dos ornamentais, que são, se assim podemos dizer, os elementos a proporcionarem a dinâmica figuracional, na qual o piabeiro é peça central.

Diante da importância dessa atividade econômica praticada pelos piabeiros nos beiradões do rio Negro e seus afluentes foi que a Prefeitura do município de Barcelos idealizou no ano de 1994 o FESPOB - Festival do Peixe Ornamental de Barcelos. Nele, o piabeiro ganhou visibilidade social. As suas práticas e sua vida sofrida ganharam destaque em meio ao duelo das agremiações de Cardinal e Acará-Disco com apresentações culturais envolvendo ritmo musical criado especificamente para o Festival, coreografias, lendas, rituais, tradições, um gigantesco trabalho plástico e uma rica produção musical. A respeito das atividades miméticas, Matos (2015) destaca que a força do marketing no Amazonas está no lazer. Dos seus sessenta e dois municípios, não há um que não desenvolva atividades festivas com intenção de atrair turistas para o seu entorno.

Contudo, mesmo em meio a essa efervescência cultural e a esse "destaque", o piabeiro vive em constantes tensões, seja lutando por um preço justo, seja por adequações trabalhistas, pois o mesmo é utilizado como mão-de-obra barata dos atravessadores, ou ainda, vive mergulhado na incerteza de como será o futuro econômico na região do rio Negro, visto que, a sustentabilidade da pesca dos ornamentais não tem sido tratada 
com a devida atenção pelos órgãos norteadores das políticas sustentáveis, assim como, pelo governo federal, estadual e pela prefeitura do município.

Dessa forma, a atividade econômica desse amazônida nos despertou um olhar atento e por meio desse trabalho buscaremos analisar as redes de interdependência imbricadas às práticas socioculturais envolvendo os piabeiros de Barcelos nesse processo de pesca, negociação e exportação dos ornamentais.

\section{A IMPORTÂNCIA ECONÔMICA DA PESCA ARTESANAL ORNAMENTAL E AS RELAÇÕES DE PODER}

A pesca artesanal ornamental iniciou no Estado do Amazonas na década de 50, mais precisamente na fronteira do Brasil com a Colômbia e Peru. Inicialmente a espécie em foco era o Acara discus (SymphysodonAequefasciatus). Depois se despertou interesse por outras espécies como o Cardinal Tetra (ParacheirodonAxelrodi), Rosacéo (HyphessobryconErythrostigma), Borboleta (CarnegiellaStrigata), Lápis-deuma-faixa (AnostomusTaeniatus), Acará-bandeira (PterophyllumScalare), Bodós (Gênero Ancistrus), Arraia-pintada (Potamotrygon Motoro).

Pesquisas do Projeto Piaba desenvolvido pela Universidade Federal do Amazonas mostram uma extrema necessidade de reposição dos plantéis desses peixes,visto que as espécies ornamentais têm o ciclo curto de vida, já que são bastante sensíveis ao "stress" gerado por inúmeras causas e também por serem espécies de ornamentais da Amazônia. Essa condição proporcionou um rápido crescimento da pesca ornamental, que migrou do alto Solimões para todo Estado, tendo hoje o médio rio Negro como seu principal nicho de produção.

Durante algumas décadas,segundo os dados da Secretaria de Produção Rural do Amazonas,o estado manteve a liderança na exportação de espécies de peixes para aquariofilia de água doce. Na década de 80, chegou a exportar até 45 milhões de indivíduos, já na década de 90, a média 
de exportação caiu para 25 milhões de espécimes, entre 2000 e 2008, a média de exportação girou em torno de 18 milhões de indivíduos e em2015uma safra de apenas 5 milhões, ou seja, aproximadamente 15\% do que se exportava nas décadas passadas.Até o ano de 2009 oestado exportava aproximadamente $85 \%$ dos peixes ornamentais exportado pelo Brasil e o rio Negro e seus afluentes produzem aproximadamente $90 \%$ dos peixes ornamentais exportados pelo Amazonas. Do volume produzido pelo rio Negro o município de Barcelos responde por 60\%, Santa Isabel por 35\% e São Gabriel por 5\%. Por essa razão Barcelos ficou conhecida como a Capital Nacional do Peixe Ornamental.

Esses dados revelam ainda que essa modalidade de pesca empregava somente na região do rio Negro aproximadamente de 13 mil pessoas e no resto do Estado algo em torno de 3.000 pessoas gerando, portanto, aproximadamente 16 mil empregos diretos. Até 2008, a atividade de pesca ornamental rendia 5 milhões de reais para o Estado, correspondendo a $60 \%$ da renda aferida pelos mesmos e algo em torno de 1 milhão de reais é gerado no resto do Estado. O valor arrecadado distribuído entre as famílias que praticam a pesca ornamental significa sustento familiar com uma atividade lícita e com forte apelo preservacionista, pois sem esse recurso, tais piabeiros e piabeiras partem para outras atividades na intenção de alimentar suas famílias, como por exemplo, pesca esportiva, atuando como guias e/ou praticando a pesca comercial, capturando quelônios ilegalmente, realizandoa caça de animais silvestres, derrubando a floresta para plantar roça e retirando madeira que pode ocasionar a degradação ambiental, assim como vem ocorrendo com o garimpo e a exploração madeireira.

Observamos que a partir de 2008, esse bionegócio entrou em franca decadência no Estado do Amazonas, no plano interno em relação ao valor exportado, perdemos o primeiro lugar para o Estado do Pará e no plano externo perdemos a supremacia para a Colômbia e o Peru. Isso 
demonstra que houve falha nas redes que sustentam essa atividade econômica, ou seja, o Estado falhou em seus mecanismos de controle e políticas adequadas ao ramo.

Alguns fatores contribuíram para esse decréscimo tais como: legislação inadequada, países vizinhos que exportam a maioria de suas espécies, com incentivos do governo; dificuldades de logística de transportes; falta de um entreposto e infraestrutura nos municípios para a recuperação do peixe capturado, diminuindo as perdas e o impacto da captura sobre as populações de peixes e dando um preço mais justo aos piabeiros; barreiras sanitárias internacionais; criação em cativeiro em outros países; falta de marketing nos centros importadores, entre outros.

O comércio de peixes ornamentais era o melhor exemplo de arranjo produtivo local (APL), cujo modo operacional foi se consolidando durante mais de cinco décadas. Nessa rede de interdependência entre a captura do peixe até sua chegada ao destino final há uma teia de relações onde o indivíduo situado no lado baixo da balança de poder é o piabeiro e acaba por receber os efeitos negativos em sua vida. Assim como o seringueiro que na história da Amazônia foi explorado na corrida pela borracha, o piabeiro é a mão de obra barata ideal para os atravessadores que operam na região.

Essas figurações, para quem é de fora pouco entende e, portanto há necessidade de explicar. Ao sair do seu local de origem, isto é, do município os piabeiros encontram-se endividados com seus patrões, pois necessitam de rancho pra viagem e para deixar parte à sua família que fica na sede do município. Também precisam fazer aquisição dos artefatos de pescas e outros produtos: redes/telas, caçapas, gasolina, diesel, lanterna, bateria ou pilha, etc. Quando não compram dos próprios atravessadores se endividamnas tabernas e mercadinhos do município através do sistema a crédito. Essa compra é um acordo moral e os gêneros alimentícios e outros produtos são anotados, junto com os valores, em um sistema de controle - 
caderno - que fica de posse do proprietário de estabelecimento comercial. Em seu retorno, o piabeiro deve, por questões morais, após vender seu peixe, ir ao ajuste de contas.

Para entregar o peixe em Manaus, o piabeiro depende de várias fases de intermediação. Após a captura o peixe é armazenado em tanques naturais cercados com telas, depois é levado ao município e entregue ao 'patrão', como os piabeiros chamam o intermediário - na maioria das vezes dono de barco, que compra o peixe em Barcelos para vender em Manaus aos exportadores. Até aí a negociação é feita em moeda nacional, mas a exportação já é realizada em dólar. Por isso, segundo dados da Secretaria de Produção Rural do Amazonas, apesar da queda na produção de peixes a exportação bateu recorde em 2015 devido à alta do dólar como mostraremos nos gráficos mais adiante.

Segundo levantamento da Sepror o valor do peixe aumenta até 4.000 vezes entre a origem e a exportação. O piabeiro ganha US $\$ 0,005$ por cardinal em Barcelos e, numa loja nos Estados Unidos, o consumidor chega a pagar US\$2,00. Daí, observamos o grande desequilíbrio na pirâmide dos lucros. Enquanto o piabeiro arrisca a vida para vender um milheiro de piabas negociado em moeda nacional por 18,00 Reais o exportador/aquaristaslucra milhões em dólares.

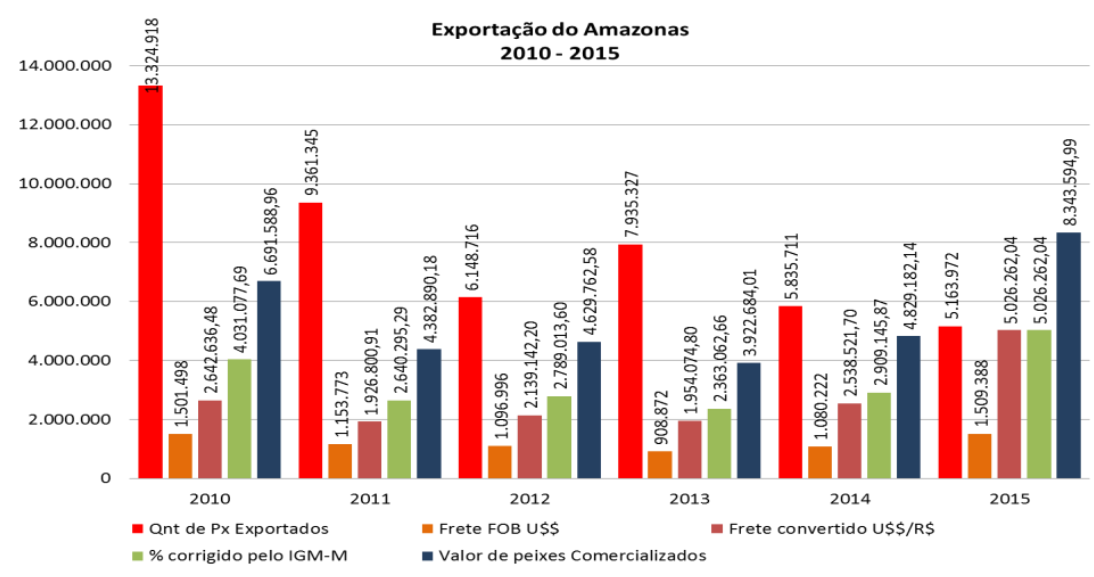




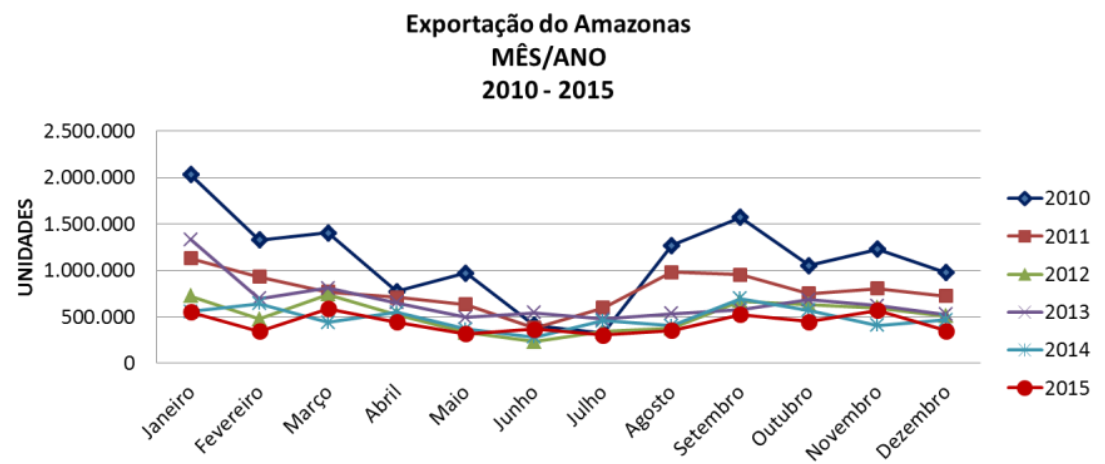

As políticas assistencialistassinalizam comoameaça ao modo de produção da economia solidária, pois algumas políticas acabam por produzir o chamado assistencialismo improdutivo que não propicia uma saída emancipatória à politica econômica coletiva (Pochmann, 2004).

Ao tratar sobre a economia solidária Pochmann (2004) mostra que essas ações mais imediatistas e pragmáticas tendem, muitas vezes, a simplesmente "reorganizar parcelas atomizadas e localizadas do excedente da força de trabalho para a promoção de inserção subordinada à economia capitalista". Tendo em vista algumas brechas do mercado, são constituídos grupos de trabalho a serem utilizados pela terceirização e subcontratação, na maioria, contudo, distante da ética da economia solidária. Como nessa região do rio Negro não existem muitas empresas do setor privado nota-se o poder público o explorador, aquele que cria subempregos em troca de votos, postos de trabalho temporário que revelam o modelo coronelista ainda em vigor na região amazônica. Ou propriamente ações de compadrio político que protegem alguns patrões da região. Alguns até entendem que o entreposto de peixes ornamentais de Barcelos ainda não foi concretizado porque viria a prejudicar os altos lucros dos atravessadores da região.

As tensões desencadeadas nessas figurações induzem aos piabeiros a trilharem em busca de respostas integradas e concertadas. Eles aguardam ação em todos os domínios, no político, no econômico, no social, no ambiental e no territorial. É assim com respostas locais e 
renovações estruturais econômicas que eles vislumbram a sustentabilidade. Com o modelo da economia solidária a base de desenvolvimento econômico é transparente e promotora da criação de emprego, viabilizando uma ética na gestão e na comunicação, privilegiando o ganho sustentável em detrimento do individual.

\section{O PIABEIRO E AS FIGURAÇÕES}

O piabeiro é resultado de um longo processo histórico de ocupação da Amazônia. Inicialmente com a predominância indígena foi dando lugar ao caboclo resultado interétcnico entre o índio, branco e negro.

Ao analisarmos os piabeiros de Barcelos à luz da Teoria Figuracional ou Processual de Norbert Elias veremos homens e mulheres que se reinventam a cada ciclo natural da região, de acordo com a dinâmica dos rios ou da necessidade socioeconômica. Seu modo de vida indica os sentidos da ação humana no curso do processo civilizador.

O piabeiro é seringueiro, piaçaveiro, guia de pesca esportiva, pescador, castanheiro, tirador de cipó, vendedor de açaí, agricultor, caçador. De acordo com a época e as estações do ano ele se reveste de uma nova sociabilidade e vai adquirindo uma nova figuração diante das dinâmicas naturais e sociais.

Ao tratar do etnoconhecimento, das práticas da agricultura, da caça, da pesca e também de grupos sociais de algumas comunidades da Amazônia o professor doutor Gláucio Campos Gomes de Matos em sua obra Ethos e Figurações na Hinterlândia Amazônica (2015) nos mostra que a Amazônia é uma invenção social e resultado do processo civilizador que segundo Elias é autônomo.A sociologia figuracional de Elias dá a fundamentação do trabalho de Matos que avança em seus estudos mostrando que a sociedade em certo espaço produz a partir do 
conhecimento acumulado o que permite possibilidades de permanência ou de rupturas. Assim, olhamos o amazônida como um homem que consegue reconstruir seu modo de vida a partir de novas dimensões e novas possibilidades, dado a dinâmica figuracional na qual se insere.

Por meio de suas descrições Matos (2015) enfatiza que "há um processo em curso". Processos esses que permeiam e entrecruzam figurações." E nesse entrelace nos defrontamos com metas e objetivos de muita gente, isto é, interesses de indivíduos que extrapolam a área pesquisada, assim como do estado e do país, o que se pode verificar, dependendo do tempo e do espaço são as mudanças no ethos. Isso é observado não só pelas redes invisíveis, mas também pelos mecanismos de controle que se apresentam em maior volume e muito mais rígidos. As figurações orientam os homens para o capitalismo ou socialismo, para as ações ecológicas, comportamento religioso, subsistência, sustentabilidade ou predação a ponto de minar as espécies e dificultando a permanência do indivíduo no espaço de sua moradia.

Com o piabeiro não é diferente, pois há necessidade de se praticar a pesca sustentável diminuindo ações predatórias na região. A fé é partícipe na vida desse caboclo e sua consciência ecológica já está sendo despertada, que segundo Matos (2015), resultado das discussões ambientais que mostram um olhar mais sensível ao ambiente, no curso do processo civilizador. Nessa figuração organização social dos piabeiros ganha novos rumos, por exemplo, com a implantação do selo verde onde os ornamentais ganharão mais qualidade e o pescador uma maior valorização trabalhista. Como nos afirma Matos (idem): “no Amazonas tudo está em processo e arraigado a ele as figurações se mostram" e paralelo a isso "a natureza segue seu percurso sem pedir licença". Nisso vemos as teias de interdependência agindo continuamente a vida dos atores desses beiradões. 


\section{OS PIABEIROS E AS PRÁTICAS SOCIOCULTURAIS}

Segundo Matos (2015), os conceitos de adaptação contribuem para entender o ethos amazônico - as práticas socioculturais. Nesse caso o caboclo torna-se interdependente da natureza e dos processos sociais se adaptando a eles conforme a necessidade.

No período do defeso, por exemplo, o piabeiro torna-se vendedor de açaí. Adentra os açaizais, sobe de peconha6 na palmeira e tira o cacho de açaí, depois faz o vinho e logo em seguida pratica a venda. Esta pode ser por encomenda ou mesmo feita pelas ruas do município em panelões ou já medido em garrafas pet. Alguns já avançaram na tecnologia e fazem a venda pelas redes sociais.

Em outro momentoo piabeiro torna-se pescador de peixes comestíveis, seja para subsistência ou para contribuir com as festas religiosas que podem ser de santos católicos ou comemorações de igrejas evangélicas espalhadas nas dezenas de comunidades rurais. É só ir numa comemoração dessas que encontraremos o moquental7 repleto de peixes de diversas variedades, carne de anta, carne de paca, mutum, jacamin, cabeçudo, tracajá, irapuca assada, pirarucu, a famosa canhanpira, e etc.

No período do Fespob - Festival do Peixe Ornamental de Barcelos alguns se tornam artesãos e serão comerciantes nas barracas espalhadas na praia grande ou na sede do município onde vendem artigos relacionados aos peixes da disputa Cardinal e Acará Disco dividindo espaço com ambulantes que vêm de fora do município. No Fespob os piabeiros que são os principais homenageados atuam como atores nas encenações, figurantes nos carros alegóricos, como empurradores de carros alegóricos ou meros espectadores. Algumas piabeiras nessa época se tornam

6 Instrumento utilizado para subir nos açaizeiros. É feito de cipó ou saco de fibra enrolado.

7 Jirau utilizado para assar a caça ou peixe. 
costureiras fazendo as roupas dos brincantes e recebendo o pagamento em dinheiro que vem das agremiações ou fazem pelo puro prazer de contribuir com seu peixe do coração.

O Fespob foi instituído em 1994 pelo decreto do prefeito Valdeci Raposo como marketing da pesca dos ornamentais. Na época o município de Barcelos alcançara o título de capital brasileira do peixe ornamental e a pesca artesanal movimentava cerca de $80 \%$ da economia do município. No evento se homenageia os dois principais objetos de exportação Cardinal e Acará Disco e também o homem que pratica a captura - o piabeiro.

No Fespob existem vários itens como: apresentador, intérprete, índia guerreira, cabocla, alegorias, ala fauna e flora, letra e música temática, coreografia, etc. Mas, o ponto máximo da apresentação é a Ala dos Piabeiros. Com música e coreografia própria quando essa ala entra há um delírio dos cardumes - como são chamadas as torcidas.Amparado em Elias e Dunning (1992), podemos identificar que na atividade mimética sendo realizada e em momentos de lazer, o descontrole controlado das emoções é um fato.

A ala dos piabeiros é composta por 40 integrantes. São filhos de piabeiros, filhos de comerciantes, filhos de professores, entre outros. A disputa é acirrada e geralmente vencida nos décimos de notas.

O Festival que ocorre no último fim de semana de Janeiro também marca praticamente o final da temporada de pesca esportiva onde o piabeiro figura como guia de pesca pilotando as pequenas lanchas chamadas de voadeiras levando os turistas aos principais lagos da região, onde devido a seca dos rios se encontram abarrotados de tucunarés.A esse assunto, Matos (2015, p.120), argumenta:

É também em nome de emoções prazerosas que a pesca esportiva se destaca na captura de tucunarés (Cichla spp). Depois de fisgado, a disputa inicia. De um lado a força da natureza contra a força do pescador alicerçado pelos artefatos tecnológicos - molinetes, varas, anzóis, garatéias e linhas de resistências suficientes para dominar a natureza do 
peixe. O pescador se excita com a força, a bravura do tucunaré voraz, que entesa a linha de pesca ao curvar a vara no sentido das profundezas do rio.

O autor, ao se distanciar, continua em suas reflexões:

Só ele sabe", nesse caso o pescador, o significado simbólico do resultado daquele momento de lazer. Poderá seu nome repercutir nas revistas especializadas ao capturar o maior peixe ou simplesmente repercutir na rodada de amigos os momentos de lazer e virar estórias de pescador. Do outro lado, mal sabe, ou melhor, o tucunaré não terá conhecimento por não compreende a linguagem dos homens, do significado ao ser dominado, içado, fotografado como troféu, beijado e com um direito a umas tapinhas no lombo e ser reposto no rio para recuperar-se.

E finaliza dizendo:

Desse momento de prazer a pior sai em favor do peixe, que depois de fisgado por anzóis e/ou garatéias, a boca, ou melhor, a cavidade bucal (cavidade bucofaringeana) poderá sair seriamente ferida. Em situação de inanição, por não poder se alimentar, o peixe emagrece, ficando cabeçudo termo local mucaua - a ponto de levá-los a morte. Entretanto, se viver, talvez seja possível um outro encontro com pescador, que pode ser esportivo, de subsistência ou profissional.

Por fim, observamos que durante o Fespob alguns piabeiros também atuam como bandeirinhas, ou seja, o piloto das voadeiras -táxis fluviais -que atravessam os brincantes da orla da cidade à áreas de praias, dentre elas, a Praia Grande localizada frente à sede do município.

Demonstrando hospitalidade, objetivando agradar aos turistas provindos de outros municípios do Amazonas - Manaus, Novo Airão, Santa Isabel e São Gabriel da Cachoeira -piabeiros promovem o espetáculo das luzes ao entorno dos barcos e lanchas, que se aproximam do porto da cidade e na extensão de sua orla. 


\section{A ORNAPESCA E O SELO VERDE}

A Cooperativa dos Pescadores e Pescadoras Ornamentais do Médio e Alto Rio Negro ORNAPESCA trabalha na filosofia da economia solidária com o intuito de valorizar os pescadores diminuindo assim, a ação dos patrões exploradores da força de trabalho desses pescadores. Quanto ao sistema de Cooperação na economia solidária segundo Domingues (2009) é a existência de interesses e objetivos comuns, a união dos esforços e capacidades, a propriedade coletiva de bens, a partilha dos resultados e a responsabilidade solidária. Essa figuração, que aponta para um equilíbrio de poder, envolve diversos tipos de organização coletiva: empresas autogestionárias ou recuperadas (assumida por trabalhadores); associações comunitárias de produção; redes de produção, comercialização e consumo; grupos informais produtivos de segmentos específicos (mulheres, jovens etc.); clubes de trocas etc. $\mathrm{Na}$ maioria dos casos, essas organizações coletivas agregam um conjunto grande de atividades individuais e familiares, que se ligam em redes enfatizando as relações de interdependências funcionais.

É nesse pensamento que trabalha a ORNAPESCA, segundo João Panadáatual presidente da cooperativaa finalidade da ORNAPESCA é trabalhar com o lado social do pescador, tirando documentação para que ele tenha vários benefícios, como por exemplo, seguro defeso, auxílio maternidade, auxílio doença, aposentadoria por idade. Ela trabalha nessa área social visando à partilha de tudo que entrar (recursos financeiros, comercialização do pescado). Segundo o representante, essa cooperativa surgiu pra trazer uma nova esperança ao pescador da região do médio rio Negro, pois o piabeiro havia sido esquecido pelo poder público. O presidente da cooperativa afirma quehouve a necessidade de uma melhor organização a fim de lutarem pelos interesses coletivos. 
A edição da Instrução Normativa Interministerial $n^{\circ} 1$, de Janeiro de 2012, de 03/01/12, trouxe algum alento ao setor, uma vez que acrescentou 393 novas espécies a lista anterior que tinha 357 espécies permitidas para a exportação, relacionando espécies como os bodós Hipancystrus sp, Ancystrus sp e Peckoltia sp, espécies de grande aceitação no mercado e com melhor valor na comercialização. Podemos citar ainda a Indicação Geográfica para os Peixes Ornamentais do rio Negro e o Convênio entre o Estado e o MPA para construção do Centro Integrado da Pesca Ornamental - CIPAR em Barcelos. O apoio do Estado à atividade, aos seus praticantes e à região é bem visto, porém o estabelecimento de regras e mecanismo de controle podem, como é de se esperar, desencadear tensões, por mexer com a autonomia e equilíbrio na balança de poder.

O Projeto de Indicação Geográfica - IG tem o objetivo de gerar informações e protocolos para estabelecer uma certificação de Indicação Geográfica de Procedência para peixes ornamentais do rio Negro, uma espécie de Selo Verde. A certificação de Indicação de Procedência tem a finalidade de gerar sustentabilidade socioeconômica para esses dois municípios, participantes iniciais do projeto, beneficiando as pessoas estabelecidas no local de produção, a preservação da história local e do produto, agregando valor a esta tipicidade, a preservação da biodiversidade, proteção de um patrimônio nacional e econômico, do manejo, da proteção dos produtores, dos consumidores de peixes ornamentais "hobistas" e da riqueza, da variedade e da imagem de seus produtos e não menos, um mecanismo de controle onde há regras muito bem estabelecidas que não permitem autonomia total ao pescador ou à cooperativa. Ou seja, ao mesmo tempo em que o estado promove a emancipação dos piabeiros em relação aos atravessadores, ele regula as ações dos mesmos.

O projeto de Indicação de Procedência dos Peixes Ornamentais do rio Negro já está em fase de finalização de montagem do dossiê para ser entregue ao Instituto de Nacional de Propriedade Industrial - INPI, mas 
ainda está esbarrando em algumas dificuldades como a complementação de informações e pagamentos de profissionais nas áreas específicas do projeto. Os custos para as etapas que seguem estão estimadas em R $\$ 1.000 .000,00$ (Um Milhão de Reais), com um tempo de execução das etapas que seguem de pelo menos dois anos com: treinamentos, cursos e aperfeiçoamento das técnicas presentes na certificação, deslocamentos de técnicos, despesas com profissionais, diárias, alimentação, combustíveis para os deslocamentos dos piabeiros, materiais de divulgação, tanques redes, participação em eventos nacionais e internacionais.

O projeto de IG está sendo conduzido e organizado pela Universidade Federal do Amazonas através do grupo do Projeto Piaba em parceria com a SEPA/SEPROR, SEBRAE, ICMbio e pleiteada pela Cooperativa de Pescadoras e Pescadores Artesanais de Peixes Ornamentais do Médio e Alto Rio Negro - ORNAPESCA. Para início foram selecionados quatro piabeiros que participarão do projeto piloto. Todos serão capacitados pelo IDAM e Sepror, onde receberão orientações técnicas quanto ao manejo, captura e pós-captura do peixe ornamental, buscando atender a demanda dos importadores visando à qualidade e um preço mais justo. Esses piabeiros seguirão protocolos definidos por meio de consultas realizadas ao longo de três anos entre exportadores, importadores, pesquisadores e próprios pescadores/piabeiros.

Nessa figuração que se mostra, os piabeiros esperam não somente a legislação e uma IG, mas também infraestrutura, financiamento e parcerias público/privado para uma atividade de grandeza nacional e internacional cujo objetivo possibilitará a sustentabilidade dos piabeiros do Amazonas, a conservação e a preservação da floresta, ou seja, ordenamento nos seus aspectos sociais, ambientais, sanitários e tributários. 


\section{CONSIDERAÇÕES FINAIS}

Como pudemos ver as teias invisíveis que envolvem o sistema de produção da pesca artesanal ornamental nos mostra vários entraves a serem vencidos. As figurações as quais os piabeiros estão inseridos norteiam sua vida, querendo ou não perpassa por interesses de grupos empresariais, políticas públicas, movimentos culturais.

No que se refere à economia solidária,vem se apresentando como uma alternativa no modo de produção dos ornamentais, pois não foca apenas a geração de renda, mas traz propostas de mudanças nas relações interpessoais e com o meio ambiente. Cooperação, não competição, preservação dos recursos naturais, não exploração dos trabalhadores, igualdade de poder na tomada de decisões na empresa e responsabilidade com a comunidade local onde o empreendimento está inserido são princípios que norteiam essa prática. Os membros da ORNAPESCA pretendem caminhar nessa linha e muito ganhará a economia do município de Barcelos.

O desafio é grande: mobilizar e articular os atores locais (incluindo o poder público), com seus interesses divergentes, para construir o ordenamento pesqueiro dessa região, ainda farta e com potencial para a convivência das diferentes modalidades de pesca, sem imobilização econômica e garantindo os direitos territoriais coletivos das populações tradicionais. E tirar o monopólio desses patrões o que Elias chama de "posse privada" quando se refere à distribuição das taxas de poder na França do século XVIII. Nisso podemos ver como as redes de interdependência se apresentam levando-nos a concordar com Matos (2015) que constatou no universo empírico mudanças na estrutura física e social das comunidades estudadas em sua obra. E assim será com os pescadores ornamentais de Barcelos. As mudanças vão acontecendo no curso do desenvolvimento da sociedade. 


\section{Referências}

DOMINGUES, Marco Paulo Tavares Sousa. Economia Solidária: A Economia Real do Desenvolvimento Sustentável. Santarém. Portugal, 2009.

ELIAS, N.\& DUNNING, E. A Busca da Excitação. Difel, Lisboa. 1992. Escritos e Ensaios: Estado, Processo, Opinião Pública. Rio de Janeiro: Jorge Zahar, 2006.

O Processo Civilizador. Volume I. Rio de janeiro: Jorge Zahar, 2006.

MATOS, Gláucio Campos Gomes de. Ethos e Figurações na Hinterlândia Amazônica. Manaus: Valer/Fapeam, 2015.

POCHMANN, M. A Economia Solidária no Brasil: Possibilidades e Limites. São Paulo: Contexto, 2004.

SEPROR, Secretaria de Estado da Produção Rural. Secretaria Executiva Adjunta da Pesca e Aquicultura. Dados 2015. 